\title{
Preventing Vectorborne Transmission of Zika Virus Infection During Pregnancy, Puerto Rico, USA, 2016-2017
}

Katherine Kortsmit, Beatriz Salvesen von Essen, Lee Warner, Denise V. D'Angelo, Ruben A. Smith, Carrie K. Shapiro-Mendoza, Holly B. Shulman, Wanda Hernández Virella, Aspy Taraporewalla, Leslie Harrison, Sascha Ellington, Wanda D. Barfield, Denise J. Jamieson, Shanna Cox, Karen Pazol, Patricia Garcia Díaz, Beatriz Rios Herrera, Manuel Vargas Bernal

We examined pregnant women's use of personal protective measures to prevent mosquito bites during the 2016-2017 Zika outbreak in Puerto Rico. Healthcare provider counseling on recommended measures was associated with increased use of insect repellent among pregnant women but not with wearing protective clothing.

$\mathrm{D}$ uring 2016-2017, Puerto Rico had active transmission of Zika virus (ZIKV). During January 27, 2016-June 10, 2017, the Puerto Rico Department of Health (PRDH) reported 40,357 confirmed cases of ZIKV infection, including 3,833 cases among pregnant women (1-3). Because of the severity of adverse birth outcomes (e.g., brain and eye abnormalities, microcephaly, other birth defects) linked to maternal ZIKV infection $(4,5)$, the Centers for Disease Control and Prevention (CDC) (6-9) and PRDH (10) released guidance for preventing ZIKV. In areas where ZIKV transmission was active, pregnant women were advised to prevent mosquito bites by wearing protective clothing (long-sleeved shirts and long pants), and by using Environmental Protection Agency (EPA)-registered insect repellent (6-10).

Author affiliations: Centers for Disease Control and Prevention, Atlanta, Georgia, USA (K. Kortsmit, B. Salvesen von Essen, L. Warner, D.V. D'Angelo, R.A. Smith, C.K. Shapiro-Mendoza, H.B. Shulman, A. Taraporewalla, L. Harrison, S. Ellington, W.D. Barfield, S. Cox, K. Pazol); Puerto Rico Department of Health, San Juan, Puerto Rico, USA (W. Hernández Virella, P. Garcia Díaz, B. Rios Herrera, M. Vargas Bernal); Emory University School of Medicine, Atlanta (D.J. Jamieson)

DOI: https://doi.org/10.3201/eid2611.201614

\section{The Study}

The Pregnancy Risk Assessment Monitoring System-Zika Postpartum Emergency Response Study (PRAMS-ZPER) was conducted in Puerto Rico by PRDH and CDC to assess women's use of measures to prevent ZIKV infection during pregnancy (11). PRAMS-ZPER, a hospital-based survey of women with a recent live birth, was implemented islandwide in 2 phases: August 28-December 3, 2016, and November 1-December 19, 2017. Hospitals with $\geq 100$ births in the year before the study period were eligible to participate. In 2016, all 36 eligible hospitals participated; in 2017, a total of 30 of 31 eligible hospitals with operating maternity wards during the study period participated.

Delivery dates were randomly sampled for each hospital, and delivery logs were used to identify women who delivered on the sampled dates. Eligibility criteria are described elsewhere $(12,13)$. In 2016, women were approached 24-36 hours after their infants were delivered (12). In 2017, because the environment after Hurricane Maria resulted in early hospital discharges, women were approached within 24 hours postdelivery unless hospital staff recommended otherwise (e.g., mothers who had not yet recuperated). Response rates were $80.6 \%$ in 2016 and $94.4 \%$ in 2017.

In previous research, we reported 2016 PRAMSZPER data on maternal use of ZIKV prevention measures (12) and on the association between provider counseling on condom use to prevent ZIKV infection and self-reported use of condoms with sex partners

${ }^{1}$ Presented in part at the 2018 CityMatCH Leadership and $\mathrm{MCH}$ Epidemiology Conference, Portland, Oregon, September 12-14, 2018. 
during pregnancy (13). In this analysis, we report on the association between counseling from prenatal care providers and women wearing protective clothing and using insect repellent during pregnancy to prevent ZIKV infection using data from 2016 and 2017. We assessed the prevalence of wearing protective clothing and using repellent overall and by select maternal characteristics (e.g., education level, marital status; Table 1). We constructed separate multivariable, survey-weighted, logistic regression models for each study year to examine maternal characteristics associated with receiving provider counseling on wearing protective clothing and using repellent to prevent mosquito bites. We constructed separate multivariable models to examine associations between factors identified a priori, including receiving provider counseling, with wearing protective clothing daily and using repellent frequently (defined as use every day in 2016 and use always in 2017) when outside during pregnancy. Each model was further adjusted for maternal characteristics, health district region, and delivery month.

Among 3,806 combined respondents in 20162017 , nearly all, $99.4 \%$, received prenatal care. Among those who received prenatal care, $87.8 \%$ participated in the Special Supplemental Nutrition Program for Women, Infants, and Children (WIC) during pregnancy, $79.0 \%$ were $20-34$ years of age, $69.5 \%$ had >high school education, and $68.6 \%$ were unmarried.
Most women reported receiving provider counseling during pregnancy to wear protective clothing in 2016 (87.1\%) and 2017 (79.8\%) (Table 1); however, few women reported wearing protective clothing daily during either year (11.3\% in 2016 and $7.9 \%$ in 2017) (Table 2). In 2016, the prevalence of wearing protective clothing was lower among women $\leq 19$ years (7.8\%; adjusted prevalence ratio [aPR] $0.46,95 \%$ CI $0.27-0.77)$ and $20-34$ years (11.1\%; aPR $0.65,95 \% \mathrm{CI}$ $0.46-0.94)$ compared with those $\geq 35$ years $(17.0 \%)$ of age and higher among women with less than a high school diploma (20.2\%; aPR 2.03, 95\% CI 1.38-2.99) and a high school diploma (13.2\%; aPR 1.33, 95\% CI 1.01-1.73) compared with those who had more than a high school education (9.9\%). In 2017, the prevalence of wearing protective clothing was lower among women 20-34 years compared with $\geq 35$ years of age (7.1\% vs $13.5 \%$; aPR 0.52, 95\% CI 0.36-0.76) and higher among women with a high school diploma compared with those with more than a high school education (10.9\% vs 7.0\%; aPR 1.55, 95\% CI 1.13-2.14). Although receiving provider counseling varied by age and WIC participation in 2016-2017 (Table 1), wearing protective clothing did not differ by receiving provider counseling during either study year (Table 2). The most common reason women reported for not wearing protective clothing was that it was too hot $(>75 \%)$.

Most women also reported receiving provider counseling during pregnancy about repellent use in

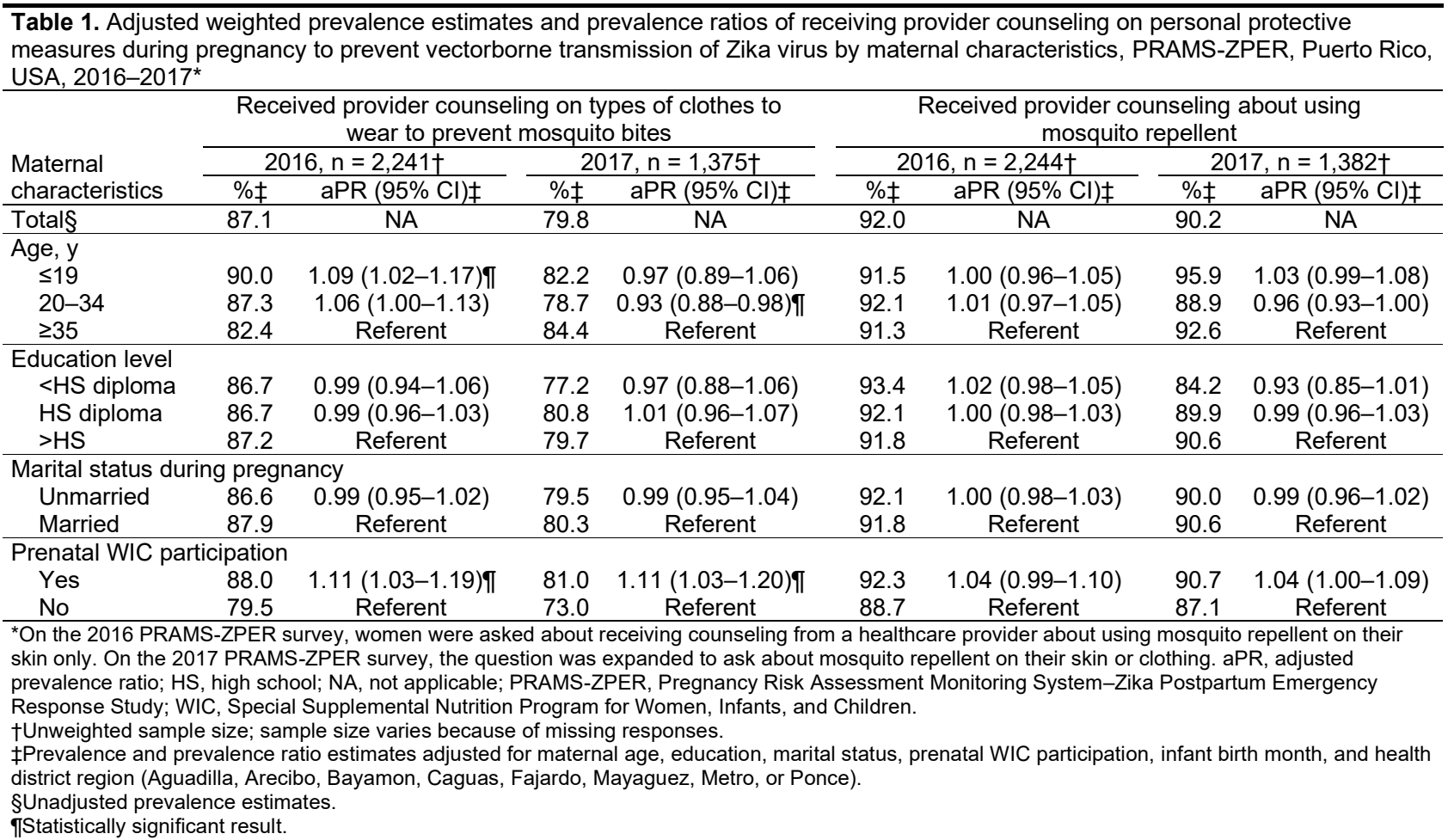


Preventing Transmission of Zika during Pregnancy

Table 2. Adjusted weighted prevalence estimates and prevalence ratios of self-reported use of personal protective measures to prevent vectorborne transmission of Zika virus during pregnancy by maternal characteristics and provider counseling, PRAMS-ZPER, Puerto Rico, USA, 2016-2017*

\begin{tabular}{|c|c|c|c|c|c|c|c|c|}
\hline \multirow{3}{*}{$\begin{array}{l}\text { Maternal } \\
\text { characteristics }\end{array}$} & \multicolumn{4}{|c|}{ Wore long sleeves and long pants every day } & \multicolumn{4}{|c|}{ Frequent mosquito repellent use $\dagger$} \\
\hline & \multicolumn{2}{|c|}{$2016, n=2,238 \ddagger$} & \multicolumn{2}{|c|}{$2017, \mathrm{n}=1,365 \ddagger$} & \multicolumn{2}{|c|}{$2016, n=2,241 \ddagger$} & \multicolumn{2}{|c|}{$2017, \mathrm{n}=1,375 \ddagger$} \\
\hline & $\% \S$ & aPR $(95 \% \mathrm{Cl}) \S$ & $\% \S$ & aPR $(95 \% \mathrm{Cl}) \S$ & $\% \S$ & aPR $(95 \% \mathrm{CI}) \S$ & $\% \S$ & aPR $(95 \% \mathrm{Cl}) \S$ \\
\hline Total| & 11.3 & NA & 7.9 & NA & 45.4 & NA & 56.9 & NA \\
\hline \multicolumn{9}{|l|}{ Age, y } \\
\hline$\leq 19$ & 7.8 & 0.46 (0.27-0.77)\# & 8.3 & $0.62(0.35-1.08)$ & 47.6 & 0.82 (0.68-0.99)\# & 53.3 & $0.87(0.73-1.04)$ \\
\hline $20-34$ & 11.1 & 0.65 (0.46-0.94)\# & 7.1 & $0.52(0.36-0.76) \#$ & 43.5 & $0.75(0.67-$ & 56.6 & $0.93(0.84-1.03)$ \\
\hline$\geq 35$ & 17.0 & Referent & 13.5 & Referent & 57.9 & Refere & 61.1 & Referent \\
\hline \multicolumn{9}{|l|}{ Education level } \\
\hline$<$ HS diploma & 20.2 & 2.03 (1.38-2.99)\# & 8.0 & $1.14(0.63-2.08)$ & 47.7 & $1.07(0.90-1.26)$ & 60.3 & $1.09(0.93-1.27)$ \\
\hline HS di & 13.2 & 1.33 (1.01-1.73)\# & 10.9 & 1.55 (1.13-2.14)\# & 46.4 & $1.04(0.93-1.15)$ & 60.6 & 1.09 (1.00-1.20) \\
\hline$>\mathrm{HS}$ & 9.9 & Referent & 7.0 & Referent & 44.8 & Referent & 55.5 & Referent \\
\hline \multicolumn{9}{|c|}{ Marital status during pregnancy } \\
\hline & 10.8 & $0.88(0.68-1.14)$ & 8.6 & $1.31(0.92-1.86)$ & 45.6 & $1.02(0.92$ & 57.4 & $1.03(0.95-1.12)$ \\
\hline & 12.3 & Referent & 6.5 & & 44.8 & Refere & 55.8 & \\
\hline \multicolumn{9}{|c|}{ Prenatal WIC participation } \\
\hline Yes & 11.2 & 0.93 & 8.1 & $.73-1.81)$ & 46.6 & $1.29(1.07$ & 58.4 & 1.20 (1.07-1.35)\# \\
\hline No & 12.1 & Referent & 7.0 & Referent & 36.0 & Refere & 48.5 & Referent \\
\hline \multicolumn{9}{|c|}{ Receipt of provider counseling on types of clothes to wear to prevent mosq } \\
\hline Yes & 11.3 & $0.99(0.73-1.35)$ & 8.2 & $1.15(0.79-1.68)$ & NA & NA & NA & NA \\
\hline No & 11.4 & Referent & 7.1 & Referent & NA & NA & NA & NA \\
\hline \multicolumn{9}{|c|}{ Receipt of provider counseling on using mosquito repellent } \\
\hline Yes & NA & NA & NA & NA & 46.1 & $1.23(1.05-1.46) \#$ & 58.9 & $1.52(1.29-1.78) \#$ \\
\hline No & NA & NA & NA & NA & 37.3 & Referent & 38.8 & Referent \\
\hline \multicolumn{9}{|c|}{$\begin{array}{l}\text { *On the } 2016 \text { PRAMS-ZPER survey, women were asked about receiving counseling from a healthcare provider about using mosquito repellent on their } \\
\text { skin only. On the } 2017 \text { PRAMS-ZPER survey, the question was expanded to ask about mosquito repellent on their skin or clothing. aPR, adjusted } \\
\text { prevalence ratio; HS, high school; NA, not applicable; PRAMS-ZPER, Pregnancy Risk Assessment Monitoring System-Zika Postpartum Emergency } \\
\text { Response Study; WIC, Special Supplemental Nutrition Program for Women, Infants, and Children. } \\
\text { †Defined as every day use in } 2016 \text { and always use in } 2017 \text {. } \\
\text { fUnweighted sample size; sample size varies because of missing responses. } \\
\text { \$Prevalence and prevalence ratio estimates adjusted for maternal age, education, marital status, prenatal WIC participation, receipt of provider } \\
\text { counseling, infant birth month, and health district region (Aguadilla, Arecibo, Bayamon, Caguas, Fajardo, Mayaguez, Metro, or Ponce). } \\
\text { TUnadjusted prevalence estimates. } \\
\text { \#Statistically significant result. }\end{array}$} \\
\hline
\end{tabular}

2016 (92.0\%) and 2017 (90.2\%); receiving counseling did not differ by maternal characteristics. Frequent repellent use was reported by $45.4 \%$ of women in 2016 and $56.9 \%$ in 2017. In 2016, frequent repellent use was lower among women $\leq 19$ years $(47.6 \%$; aPR 0.82 , 95\% CI 0.68-0.99) and 20-34 years (43.5\%; aPR 0.75, $95 \%$ CI $0.67-0.85$ ) compared with those $\geq 35$ years of age (57.9\%). During 2016-2017, frequent repellent use was higher among women receiving WIC (46.6\%; aPR $1.29,95 \%$ CI $1.07-1.57$ in 2016; $58.4 \%$; aPR $1.20,95 \%$ CI $1.07-1.35$ in 2017) compared with those not receiving WIC (36.0\% in 2016 and $48.5 \%$ in 2017). Women who received provider counseling on using repellent were also more likely to report frequent repellent use compared with women not receiving counseling in both 2016 (46.1\% vs. $37.3 \%$; aPR 1.23, 95\% CI 1.05-1.46) and 2017 (58.9\% vs. 38.8\%; aPR 1.52, 95\% CI 1.29-1.78). The most common reason women reported for not using repellent was forgetting to apply or reapply it $(>50 \%)$.

\section{Conclusions}

Most women reported being counseled by a prenatal healthcare provider during pregnancy on using repellent and wearing protective clothing to prevent ZIKV infection from mosquito bites. Provider counseling about repellent use was associated with a higher prevalence of frequent repellent use. This finding is consistent with our previous analysis of PRAMSZPER data, which showed receiving provider counseling was associated with a higher prevalence of condom use to prevent sexual transmission of ZIKV infection during pregnancy (13). In contrast, no significant association was found between receiving provider counseling and wearing protective clothing. Efforts to improve use of other risk-reduction strategies to prevent mosquito bites (e.g., repellent use, removal of standing water, screens on windows) may be beneficial, particularly when barriers, such as hot tropical climates, make wearing protective clothing less feasible. In 2017, the questionnaire was modified to include a question about using repellent on clothing in addition to exposed skin. In addition, changes in conditions after Hurricane Maria may have contributed to the increase in reported repellent use. During the ZIKV outbreak, WIC also implemented efforts to provide participants with targeted education on ZIKV prevention strategies and a prevention 
kit containing condoms, repellent, a bed net, and larvicide (14), which may partially explain increased use of repellent among WIC participants in our analysis. We found a significant association between WIC participation and frequent use of repellent but were unable to further assess the frequency or type of prenatal education WIC recipients received regarding repellent use. Of note, during 2016 only, women were asked whether they received a WIC Zika prevention kit; $77 \%$ reported receiving a kit, demonstrating the broad reach of WIC services related to ZIKV prevention among this study sample.

During prenatal care visits, healthcare providers can help prevent ZIKV infection by counseling pregnant women and their partners about risk-reduction strategies. Provider counseling on repellent and condom use were both associated with increased adoption of practices that reduce the risk of ZIKV infection (13). Findings from this study can be applied more broadly to the prevention of other vectorborne diseases among pregnant women, such as dengue, chikungunya, and malaria (7).

\section{Acknowledgments}

We thank Margaret Honein for providing support during this project.

\section{About the Author}

Dr. Kortsmit is an epidemiologist at the Centers for Disease Control and Prevention in Atlanta, Georgia, USA. Her primary research interest is women, children, and family health.

\section{References}

1. Departamento de Salud de Puerto Rico. Weekly report on arbovirus diseases (ArboV) of the Puerto Rico Department of Health, 2016 Jan 27 [in Spanish] [cited 2019 Oct 24]. http:/ / www.salud.gov.pr/Estadisticas-Registros-yPublicaciones/Informes\%20Arbovirales/Reporte\%20 ArboV\%20semana\%202-2016.pdf

2. Departamento de Salud de Puerto Rico. Weekly report on arbovirus diseases (ArboV) of the Puerto Rico Department of Health, 2016 Jun 23 [in Spanish] [cited 2019 Oct 10]. http:/ / www.salud.gov.pr/Estadisticas-Registros-yPublicaciones/Informes\%20Arbovirales/Reporte\%20 ArboV\%20semana\%2023-2017.pdf

3. Shapiro-Mendoza CK, Rice ME, Galang RR, Fulton AC, VanMaldeghem K, Valencia Prado M, et al. Zika Pregnancy and Infant Registries Working Group. Pregnancy outcomes after maternal Zika virus infection during pregnancy - U.S. territories, January 1, 2016-April 25, 2017. MMWR Morb
Mortal Wkly Rep. 2017;66:615-21. https://doi.org/10.15585/ mmwr.mm6623e1

4. Rasmussen SA, Jamieson DJ, Honein MA, Petersen LR. Zika virus and birth defects-reviewing the evidence for causality. N Engl J Med. 2016;374:1981-7. https://doi.org/10.1056/ NEJMsr1604338

5. Centers for Disease Control and Prevention. Congenital Zika syndrome and other birth defects. 2018 [cited 2019 Jan 2]. https:/ / www.cdc.gov/pregnancy/zika/testing-follow-up/ zika-syndrome-birth-defects.html

6. Petersen EE, Staples JE, Meaney-Delman D, Fischer M, Ellington SR, Callaghan WM, et al. Interim guidelines for pregnant women during a Zika virus outbreak - United States, 2016. MMWR Morb Mortal Wkly Rep. 2016;65:30-3. https:/ / doi.org/10.15585/mmwr.mm6502e1

7. Centers for Disease Control and Prevention. Avoid bug bites. 2019 [cited 2019 Sep 5]. https:// wwwnc.cdc.gov/travel/ page/avoid-bug-bites

8. Oduyebo T, Igbinosa I, Petersen EE, Polen KND, Pillai SK, Ailes EC, et al. Update: interim guidance for health care providers caring for pregnant women with possible Zika virus exposure-United States, July 2016. MMWR Morb Mortal Wkly Rep. 2016;65:739-44. https:/ / doi.org/10.15585/ mmwr.mm6529e1

9. Oduyebo T, Polen KD, Walke HT, Reagan-Steiner S, Lathrop E, Rabe IB, et al. Update: interim guidance for health care providers caring for pregnant women with possible Zika virus exposure-United States (including U.S. territories), July 2017. MMWR Morb Mortal Wkly Rep. 2017;66:781-93. https:/ / doi.org/10.15585/mmwr.mm6629e1

10. Departamento de Salud de Puerto Rico. Zika virus pregnancies [Spanish]. 2016 [cited 2019 Nov 13]. http:/ / www. salud.gov.pr/Sobre-tu-Salud/Pages/Zika-Embarazadas.aspx

11. Puerto Rico Pregnancy Risk Assessment Monitoring System - Zika Postpartum Emergency Response. PRAMS-ZPER 2.0 protocol 2017 [cited 2019 Jan 2]. https:/ / www.cdc.gov / prams/special-projects/zika/docs/pdf/english/PRAMS_ ZPER-2.0_Protocol_FINAL_508tagged.pdf

12. D'Angelo DV, Salvesen von Essen B, Lamias MJ, Shulman H, Hernandez-Virella WI, Taraporewalla AJ, et al. Measures taken to prevent Zika virus infection during pregnancy - Puerto Rico, 2016. MMWR Morb Mortal Wkly Rep. 2017;66:574-8. https://doi.org/10.15585/mmwr.mm6622a2

13. Salvesen von Essen B, Kortsmit K, Warner L, D'Angelo DV, Shulman HB, Virella WH, et al., Puerto Rico Department of Health, Women's Health and Fertility Branch, Division of Reproductive Health, National Center for Chronic Disease Prevention and Health Promotion, Centers for Disease Control and Prevention. Preventing sexual transmission of Zika virus infection during pregnancy, Puerto Rico, USA, 2016. Emerg Infect Dis. 2019;25:2115-9. https:/ / doi.org/ 10.3201/eid2511.190915

14. Earle-Richardson G, Prue C, Turay K, Thomas D. Influences of community interventions on Zika prevention behaviors of pregnant women, Puerto Rico, July 2016-June 2017. Emerg Infect Dis. 2018;24:2251-61. https:/ / doi.org/10.3201/ eid2412.181056

Address for Correspondence: Katherine Kortsmit, Centers for Disease Control and Prevention, 4770 Buford Highway, Mailstop

S107-2, Chamblee, GA 30341, USA; email: nlv2@cdc.gov 